\title{
Special Section: Economic Analyses in Business Administration
}

\author{
Peter-J. Jost ${ }^{1}$ - Alfred Wagenhofer ${ }^{1}$
}

Published online: 18 January 2018

(C) Schmalenbach-Gesellschaft für Betriebswirtschaft e.V. 2018

In September 2016, the German Economic Association of Business Administration, GEABA e. V., organized the XVII. Symposium on the Economic Analysis of the Firm at the University of Basel, Switzerland. As in prior years, all contributions presented at the Symposium used economic instruments and methods such as game theory, contract theory, empirics or experiments to study business problems. Sessions were organized along a broad set of topics in business administration, such as the international taxation, business ethics, trading and stock markets, incentive design, mandatory disclosure, corporate governance, and environmental responsibility.

This issue includes two articles that were presented at the Symposium and the comments by the discussants. Both articles were subject to the normal review process of the Schmalenbach Business Review. Although heterogeneous in their topics and methods, the articles nicely illustrate how the Symposium's main objectives are met.

The starting point of the first article "Valuing the Tax Shield under Asymmetric Taxation" by Lutz Kruschwitz and Andreas Löffler is the puzzle between theoretical predications and empirical studies concerning the relevance of tax benefits from debt in corporate valuation: While most analytical models imply that tax benefits should be significant when valuing companies, this result is not observed empirically. The literature attributes this observation to the use of a constant tax rate in valuation models, whereas gains and losses are asymmetrically taxed. Papers that integrate non-constant tax rates on the value of the tax shield employ either empirical methods or simulation studies. The authors extend this research by introducing a model that allows for a closed-form analytical solution. Their results show that, although there

P.-J. Jost

Peter-J.Jost@whu.edu

1 Lehrstuhl für Organisationstheorie, Chair of Organization Theory, WHU - Otto Beisheim School of Management, Burgplatz 2, 56179 Vallendar, Germany 
can be substantial differences between symmetric and asymmetric taxation, these differences are not large enough to explain the empirical findings. Asymmetric taxation, therefore, is not sufficient to explain the puzzle of tax shield valuation. In his discussion of the paper, Ulrich Schäfer recognizes the authors' contribution to the literature and discusses some limitations of their framework.

In the second article, "Working from Home", Kira Rupietta and Michael Beckmann empirically study the question how working from home influences employees' work effort. Unlike prior literature that uses small samples, the authors exploit a large, individual-level dataset from the German Socio-Economic Panel (SOEP), which allows them to investigate this question across all industries and occupations. The authors find that there exists a positive correlation of working from home with work effort provided by employees. Moreover, accounting for the working from home frequency, they show a positive correlation between this measure and work effort. Tim Klopries is the discussant of this paper. He relates the study to the literature and critically comments on the employed proxy of work effort and on causality also towards intrinsic motivation.

The local organizers of the XVII. Symposium, Sabine Böckem, Ulf Schiller and their team as well as the University of Basel deserve many thanks for making this conference possible. Special thanks go to the members of GEABA's Scientific Advisory Board, which handled the referee process for Symposium papers and to the presenters and discussants at the Symposium.

Peter-J. Jost, Alfred Wagenhofer 